\title{
Feeding and eating behaviors in children with autism and typically developing children
}

\author{
Comentado por: Fernanda Prada Machado', Maria Claudia Cunha², Ruth Ramalho Ruivo Palladino ${ }^{3}$
}

Martins Y, Young RL, Robson DC. Feeding and eating behaviors in children with autism and typically developing children. J Autism Dev Disord. 2008;38(10): $1878-87$.

Nos últimos anos, vários estudos vêm abordando os problemas alimentares em crianças com distúrbio do espectro autista (DEA). Apesar do crescente interesse pelo tema, esse é um assunto ainda pouco estudado e que necessita de pesquisas mais aprofundadas.

A pesquisa realizada na Universidade de Flinders (Adelaide, Austrália), tema do artigo em foco, apresenta resultados que corroboram os achados nessa área.

No estudo em questão, realizado a partir de um questionário dirigido a mães de crianças com DEA e de crianças com desenvolvimento típico, as condutas alimentares foram investigadas, descritas e analisadas.

Os autores levantaram relevantes dados de literatura que, além de abordarem as alterações descritas nos quadros incluídos no espectro autista (de socialização, comunicação e cognição), trazem informações sobre outras condutas frequentemente encontradas nestes quadros, como as alimentares.

É do conhecimento de clínicos, pais ou cuidadores de crianças com DEA que muitas dessas crianças têm preferências alimentares idiossincráticas e condutas alimentares não usuais. No entanto, existem pesquisas que mostram achados dessas mesmas peculiaridades alimentares, presentes também em crianças com outros atrasos no desenvolvimento. Nesta medida, os autores do artigo enfatizam a importância da realização de novas pesquisas para melhor esclarecerem as peculiaridades alimentares, encontradas nas crianças com diagnóstico incluído no espectro autista.

Segundo os autores, apesar das pesquisas recentes terem agregado informações no que se refere às condutas alimentares das crianças com distúrbio do espectro autista, ainda não foi esclarecido se as dificuldades alimentares manifestas por essas crianças são diferentes daquelas manifestas por crianças com desenvolvimento típico.

Afirmam, também, que isso teria implicações importantes não só para fins diagnósticos, como também para a implementação de estratégias clínicas.

Assim, o estudo em questão visou comparar as condutas

(1) Pós-graduanda (Doutorado) da Pontifícia Universidade Católica de São Paulo - PUC-SP - São Paulo (SP), Brasil.

(2) Professora titular da Faculdade de Fonoaudiologia da Pontifícia Universidade Católica de São Paulo - PUC-SP - São Paulo (SP), Brasil.

(3) Doutora, Professora da Faculdade de Fonoaudiologia da Pontifícia Universidade Católica de São Paulo - PUC-SP - São Paulo (SP), Brasil.

Endereço para correspondência: Fernanda Prada Machado. R. Albuquerque Lins, 958/11, São Paulo (SP), Brasil, CEP: 01230-000.

E-mail: femachado@uol.com.br alimentares de crianças com DEA com as crianças com desenvolvimento típico, igualadas em níveis de funcionamento adaptativo.

Vale salientar que os níveis de funcionamento adaptativo foram estabelecidos, após a aplicação de um instrumento específico: Vineland Adaptive Behavior Scales-Interview Edition $\left(\mathrm{VABS}^{(1)}\right)$. O VABS é um questionário semi dirigido que permite medir o grau de autonomia de pessoas, desde o nascimento até a vida adulta, nas áreas de comunicação, habilidades de vida diária, socialização e habilidades motoras.

A severidade do quadro foi constatada por meio da escala Childhood Autism Rating Scale (CARS $\left.{ }^{(2)}\right)$.

$\mathrm{O}$ estudo avaliou o tipo e a frequência de problemas alimentares manifestos por estes dois grupos de crianças, além da relação entre a severidade do distúrbio do espectro autista e a dos problemas alimentares manifestos.

Como objetivo secundário, os autores examinaram, nos dois grupos de crianças, a relação entre as tentativas e condutas dos pais em controlar as condutas alimentares de seus filhos. Essa comparação foi fundamentada em resultados de pesquisas que sugerem que as respostas dos pais aos problemas de alimentação de seus filhos podem efetivamente contribuir para promover e/ou superar condutas problemáticas apresentadas por estas crianças.

Nessa pesquisa, foi aplicado e respondido pelas mães de ambos os grupos de crianças, um questionário sobre os próprios hábitos alimentares e os de seus filhos. Participaram da pesquisa 82 mulheres com, no mínimo, 18 anos de idade e com, pelo menos, um filho com idade entre dois e 12 anos.

O estudo procurou expandir os resultados de pesquisas nesta área em três dimensões. Primeiro, comparando as condutas alimentares de crianças com DEA e crianças com desenvolvimento típico, utilizando parâmetros de adaptação funcional, o que permite uma possível explicação para as diferenças alimentares. Segundo, crianças com DEA foram comparadas aos seus irmãos com desenvolvimento típico para controlar as diferenças do ambiente intra familiar que afetam as condutas alimentares. Terceiro, investigou as condutas alimentares das mães, suas respostas emocionais e comportamentais e a implicação que tais reações têm sobre as condutas e hábitos alimentares de seus filhos.

Os resultados ilustram, sobretudo, que crianças com DEA são mais suscetíveis a apresentar problemas alimentares quando comparadas a crianças com desenvolvimento típico. As categorias de problemas alimentares levantadas foram: habilidades de auto-alimentação, recusa de alimentos, 
comportamentos alimentares ritualísticos e níveis de fobia a determinados alimentos.

As crianças com DEA apresentaram menos habilidades de auto-alimentação, mais recusas e, também, exibiram comportamentos fóbicos por alimentos.

Contudo, os achados do estudo indicam que crianças com distúrbio do espectro autista não demonstram diferenças marcantes comparadas às crianças com desenvolvimento típico, em termos do tipo de problemas alimentares apresentados.

Mas, o que é criticamente diferente entre estes dois grupos de crianças, é a frequência com que exibem condutas alimentares problemáticas: $67 \%$ nas crianças com DEA e $33 \%$ nas crianças com desenvolvimento típico. Os dados indicam ainda que crianças com DEA são, aproximadamente, duas vezes mais suscetíveis a apresentar problemas alimentares do que aquelas com desenvolvimento típico.

Dentre as crianças com DEA, as que apresentaram maior dificuldade adaptativa para mudanças, mostraram mais problemas referentes aos hábitos e condutas alimentares.

É importante assinalar que esses dados devem ser considerados pelos clínicos que trabalham as questões de alimentação destas crianças, considerando que elas podem ser mais lentas na superação dos problemas alimentares. Isto é confirmado, mesmo quando é levado em consideração que os tipos de problemas alimentares apresentados por essas crianças (com DEA) são similares àqueles apresentados pelas crianças com desenvolvimento típico.

As conclusões do estudo em análise indicam que é importante distinguir os problemas alimentares apresentados por crianças com distúrbio do espectro de autismo, das características peculiares desse quadro clínico, apesar de considerar que as condutas alimentares destas crianças são também encontradas nas crianças com desenvolvimento típico, embora com menor frequência.

Pesquisas dessa natureza fornecem fundamentos importantes para a clínica fonoaudiológica, no sentido de privilegiar os problemas alimentares na intervenção terapêutica, especialmente nos casos de DEA.

Destaca-se que estudos desenvolvidos por fonoaudiólogos brasileiros $^{(3-5)}$ apontam para essa mesma direção, revelando as co-ocorrências de problemas de linguagem oral e de alimentação e a importância de considerarmos as funções simbólicas desempenhadas pela região oral desses pacientes.

\section{REFERÊNCIAS}

1. Sparrow S, Balla D, Cicchetti, D. Vineland Adaptive Behavior Scales (Survey Form). Minnesota: Circle Pines; 1984.

2. Schopler E, Reichler RJ, DeVellis RF, Daly K. Toward objective classification of childhood autism: Childhood Autism Rating Scale (CARS). J Autism Dev Disord. 1980;10(1):91-103.

3. Machado FP, Cunha MC, Palladino RRR. Doença do refluxo gastroesofágico e retardo de linguagem: estudo de caso clínico. PróFono. 2009;21(1):81-3.
4. Palladino RRR, Cunha MC, Souza LAP. Language and eating problems in children: co-occurrences or coincidences? Pró-Fono. 2007;19(2):20514.

5. Palladino RRR, Souza LAP, Cunha, MC. Transtornos de linguagem e transtornos alimentares em crianças. Psicanál Univ. 2004;21:95-108. 